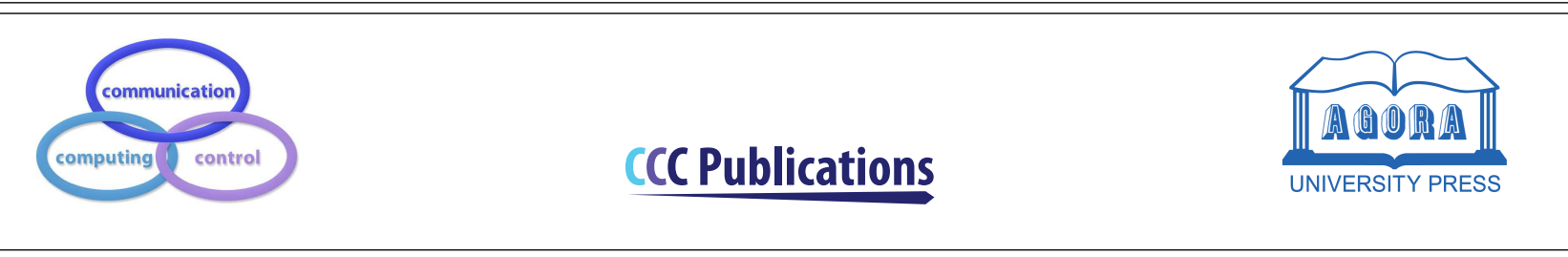

\title{
A Model to Evaluate the Organizational Readiness for Big Data Adoption
}

\author{
M. Nasrollahi, J. Ramezani
}

\author{
Mahdi Nasrollahi \\ Imam Khomeini International University (IKIU) \\ Qazvin, IRAN \\ m.nasrollahi@soc.ikiu.ac.ir \\ Javaneh Ramezani* \\ 1. NOVA University of Lisbon, Faculty of Sciences and Technology \\ Campus da Caparica, 2829-516 Monte Caparica, Portugal \\ m.ramezani@campus.fct.unl.pt \\ 2. UNINOVA-CTS \\ Campus da Caparica, 2829-516 Monte Caparica, Portugal \\ *Corresponding author: ramezanijavaneh@gmail.com
}

\begin{abstract}
Evaluating organizational readiness for adopting new technologies always was an important issue for managers. This issue for complicated subjects such as Big Data is undeniable. Managers tend to adopt Big Data, with the best readiness. But this is not possible unless they can assess their readiness. In the present paper, we propose a model to evaluate the organizational readiness for Big Data adoption. To accomplish this objective, firstly, we identified the criteria that impact organizational readiness based on a comprehensive literature review. In the next step using Principal Component Analysis (PCA) for criterion reduction and integration, twelve main criteria were identified. Then the hierarchical structure of criteria was developed. Further, Fuzzy BestWorst Method (FBWM) has been used to identify the weight of the criteria. The finding enables decision-makers to appropriately choose the more important criteria and drop unimportant criteria in strengthening organizational readiness for Big Data adoption. Statistics-based hierarchical model and MCDM based criteria weighting have been proposed, which is a new effort in evaluating organizational readiness for Big Data adoption.
\end{abstract}

Keywords: organizational readiness, big data adoption, industry 4.0, fuzzy best-worst method, principal component analysis.

\section{Introduction}

The transformation of industrialized economies from a manufacturing base to a service orientation is an ongoing phenomenon. Contemporary, developments in information and communication technology helped organizations to access information about their market, competitors, customers, partners 
and ... more easily and quickly, and this can positively impact their business processes. Furthermore, due to the rise of ever-tougher challenges in the ever-changing business environments characterized by high complexity and uncertainty, there is a clear need to respond in almost real-time to upcoming business challenges and opportunities [3]. Besides, one of the most important outcomes of the emerging Fourth Industrial Revolution (Industry 4.0) paradigm empowered by the integration of Internet of Things (IoT) technology into industrial value creation is the large generating volumes of data [19]. For these reasons, con-temporary developments in information and communication technology, and growing competitiveness have led to the emergence of the real-time Big Data analytic as a new enabler of sustainable development and sustainable competitive advantage [11].

Knowledge is a fundamental source of competitive advantage. Therefore, mining data to extract useful information about competitors, customers, suppliers, etc. and also to observe and track trends and changes in the business environment is becoming extremely beneficial for making intelligent business decisions. Big Data and its associated technologies are now relevant across industries and economic sectors [11], [22], [24].

While the term "Big Data" has been defined in different ways in the related literature sources, there is still no concrete definition to this term itself. The first concepts predominantly associated with Big Data are far from new and relate to data storage and data analysis. This is in part due to the role of digital data- available in fast-growing amounts - being produced by data-intensive organizations [22]. The fundamental notion primarily describes Big Data using the "3 Vs": Volume (referring to the amount of data), Velocity (relating to speed by which data is generated and delivered), and Variety (referring to diversity of data sources and formats) [5]. Soon the idea evolved to "5 Vs" by adding Veracity (referring to data quality) and Value (relating to the benefits from the use of data) to the former "3 Vs" [4]. Recently, Big Data has been characterized "by 7 Vs: Volume, Velocity, Variety, Veracity, Variability Visualization, and Value [12]. These characteristics of Big Data have been explained in a recent literature review [18]. In a nutshell, Big Data, as identified by [6], is a combination of architectures and innovative technologies designed to capture the value and vital information from vast volumes of data in different variety, resulting in data analysis and high-velocity capture.

In this regard, the field of Big Data adoption looks at how we can analyze, systematically extract information from, or in other words, deal with Big Data [22], [24]. The foremost opportunity and benefit Big Data adoption presents is resourcefulness in terms of cost, productivity, and competitiveness. Big Data adoption in enterprises soared from 17\% in 2015 to 59\% in 2018, reaching a Compound Annual Growth Rate (CAGR) of $36 \%$ [26]. Nevertheless, according to a comprehensive Big Data analytic study, only $14 \%$ of enterprises have put Big Data projects into production [27]. Again, according to [26], "there is a strong upward trend in adoption and a corresponding drop in those with no plans." Against this background, Big Data adoption decisions involve high levels of uncertainty and complexity that most are related to the sophisticated technology and infrastructural requirements for organizations. Therefore, there is a need for a more systematic and appropriate study of tools for assessing the potential of organizations to develop Big Data implementation. Accordingly, this paper has attempted to develop a model to measure the level of organizational readiness for Big Data adoption following the objectives listed below:

(1) Identifying the criteria that are involved in evaluating the organizational readiness for Big Data adoption.

(2) Reduction and integrating of criteria using factor analysis and developing the hierarchical structure.

(3) Determining the weights of criteria using the fuzzy BWM method.

(4) Establishing hierarchy among criteria.

The remainder of this paper is organized as follows. Section two briefly describes the design and methodology of the research. Section 3 highlights the critical criteria for evaluating organizational readiness. Section 4 provides an overview of fuzzy BWM and highlights the detailed procedure for determining the importance of criteria using fuzzy BWM; describing the fuzzy-ISM and using it for modeling criteria is discussed in section 5. The last section presents the conclusion and further research directions. 


\section{Research methodology}

Research methods are the strategies, processes, or techniques utilized in the collection of data or evidence for analysis in order to uncover new information or create a better understanding of the topic. The main purpose of this study is to identify and rank the organizational readiness criteria for Big Data adoption. To fulfill this objective, we applied field data with a focus on large scale organizations and experts with experience or expertise in this field. We need to perform a preliminary factor analysis and item reduction of evaluation criteria to achieve this purpose. Completing the factor analysis and modification of items is essential for several reasons. First, the number of identified criteria is 50 items and is too long, and some criteria have repetitive meaning. Second, several criteria required consistent clarification.

For factor analysis, a principal component analysis (PCA) was selected to consolidate the criteria. We applied an internet-based questionnaire to gather data from a sample of experts around the world. The questionnaires were sent to respondents through an email process and messages on LinkedIn. From 5th-10th September 2019, a questionnaire was sent to 2120 experts. The limited available space does not allow to provide more details about questionnaires and experts. A total of 246 answers from experts were received over 30 days. 39 answers were eliminated as not being correctly completed. Finally, only answers from 207 experts that completed the survey were kept for an analysis. Thus, data from 207 experts were included in the data set yielding a valid response rate of 9.8 percent. All data were analyzed with version 25.0 of IBM SPSS. Table 1 shows the demographics of the sample.

Table 1: Sample demographics

\begin{tabular}{|c|c|c|c|}
\hline \multicolumn{2}{|l|}{ Item } & $\mathrm{N}$ & $\%$ \\
\hline \multirow{8}{*}{ Job title } & Managing Director & 34 & $16 / 4$ \\
\hline & Vice president & 20 & $9 / 7$ \\
\hline & Consultant & 33 & $15 / 9$ \\
\hline & University & 45 & $21 / 7$ \\
\hline & sor/Lecturer & & 1210 \\
\hline & $\begin{array}{l}\text { Information } \quad \text { system } \\
\text { manager }\end{array}$ & 27 & $13 / 0$ \\
\hline & Researcher & 38 & $18 / 4$ \\
\hline & Other & 10 & $4 / 8$ \\
\hline \multirow{5}{*}{ Education } & Bachelor's degree & 4 & $1 / 9$ \\
\hline & Master's degree & 76 & $36 / 7$ \\
\hline & Professional degree & 8 & $3 / 9$ \\
\hline & Doctorate & 106 & $51 / 2$ \\
\hline & Postdoctoral & 13 & $6 / 3$ \\
\hline \multirow{5}{*}{ Age } & Under 24 & 3 & $1 / 4$ \\
\hline & $25-34$ & 92 & $44 / 4$ \\
\hline & $35-44$ & 76 & $36 / 7$ \\
\hline & $45-54$ & 31 & $15 / 0$ \\
\hline & Over 55 & 5 & $2 / 4$ \\
\hline & $1-5$ & 43 & $20 / 8$ \\
\hline & $6-10$ & 82 & $39 / 6$ \\
\hline \multicolumn{2}{|c|}{ Work experiencel1-15 } & 29 & $14 / 0$ \\
\hline & $16-20$ & 44 & $21 / 3$ \\
\hline & Over 21 & 9 & $4 / 3$ \\
\hline Total & 207 & 100 & \\
\hline
\end{tabular}

Figure 1 shows various steps of research process. 


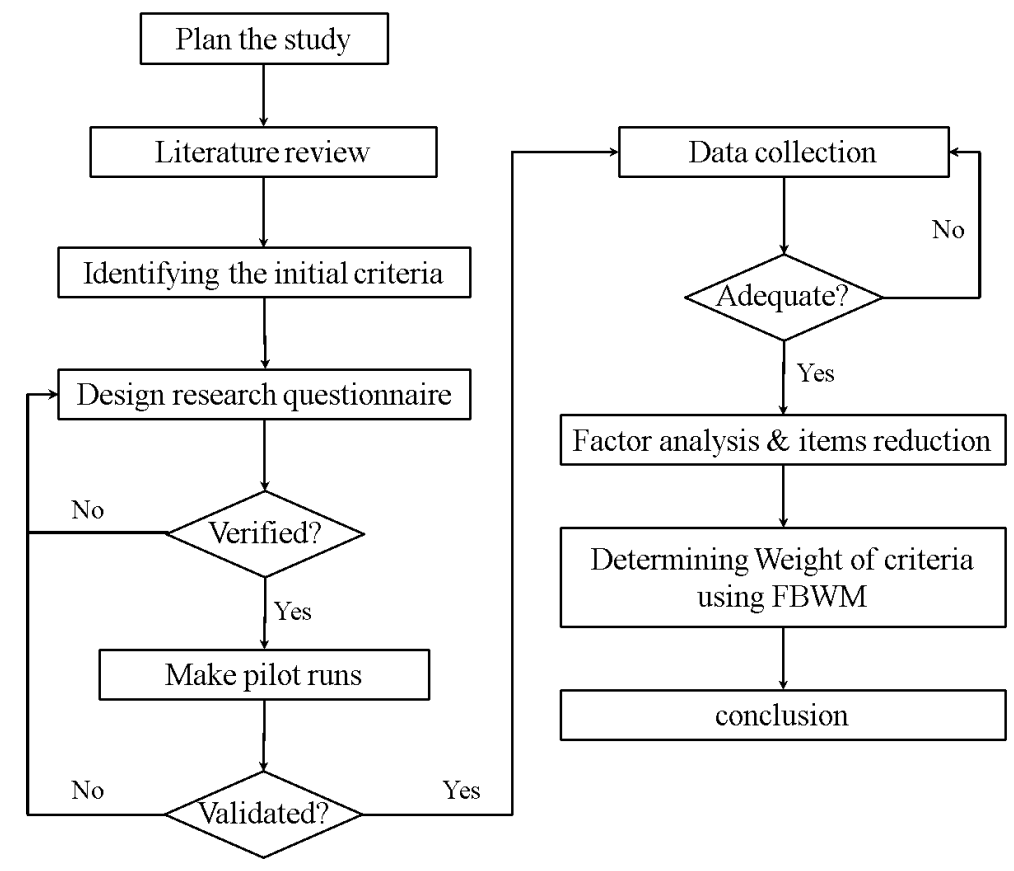

Figure 1: Research process

\section{Identification of Organization Readiness Criteria}

Although organizations invest in Big Data for its recognized benefits, the actual realization of Big Data benefits lies in the complete readiness of organizations to adopt Big Data. Based on a comprehensive review of the relevant literature, 50 initial criteria for evaluating organizational readiness for Big Data adoption have been identified (Table 2).

An initial sample of 30 experts was completed the questionnaire's 50-item draft version. Cronbach's alpha was applied to verify the internal consistency of the constructs and to measure the scale reliability. The results in Table 3 show that the alpha value is above 0.7 , and constructs are consistent accordingly. Data normality must be evaluated before running the statistical tests. The normality of the data was tested at a meaning level of $5 \%$ using the K-S test. The level of significance for all constructs was greater than 5 percent, so the data had a normal distribution.

The adequacy of the data set was determined by the use of Bartlett's test for sphericity and the "Kaiser Meyer Olkin" measure of sampling adequacy. As specified in Table 4, Bartlett's test for sphericity was significant $(P<0.05)$, and the KMO index was 0.916 ; therefore, the sample was determined to be adequate for further analysis.

Principal component analysis (PCA) is a method of consolidating mutually correlated criteria to a smaller number of criteria [9]. After the PCA is run, Eigenvalue is analyzed to aid in selecting the number of factors that have to be extracted as part of the next step. Table 5 aid in deciding the number of criteria to be obtained. From Table 5, it is seen that criterion 12 has a variance of 1.326; and variance of 1.0 and above shows that there is considerate variability in the criterion. Thus, it leads to con-ducting a 12-criterion extraction.

In an attempt to propose the underlying theme or criterion within each domain, the research team, grouped the items from the matrix of pattern correlation using the varimax rotation on these 12 domains. Rotation optimizes the criterion structure and improves the interpret ability of the criterion solution. The unrotated and varimax rotation factors were analyzed, and the variables were categorized under criteria based on their maximum absolute value. The result was a decrease from 50 criteria in the initial study to 12 criteria. A name was selected for each criterion according to the type and structure of the criteria. Figure 2 shows the hierarchical structure of organizational readiness evaluation criteria for big data adoption. 
Table 2: Factors affecting Big Data adoption

\begin{tabular}{|c|c|}
\hline Criteria & References \\
\hline Appropriateness & {$[24],[2],[23]$} \\
\hline Availability of Big Data tools & {$[2],[17],[13]$} \\
\hline Big Data awareness & {$[8],[16]$} \\
\hline Business strategy orientation & {$[24],[2]$} \\
\hline Change efficacy & {$[24],[2]$} \\
\hline $\begin{array}{l}\text { Competitive (Perceived industrial pres- } \\
\text { sure) }\end{array}$ & {$[24],[2],[13],[14],[10],[25],[1],[15]$} \\
\hline Complexity & {$[24],[2],[16],[14],[15]$} \\
\hline Cost of adoption & {$[24],[2],[15]$} \\
\hline Data control & {$[2],[1]$} \\
\hline Data quality and integration & {$[22],[12],[2],[17],[10],[25],[1],[15]$} \\
\hline Decision-making culture & {$[24],[2]$} \\
\hline Firm size & {$[24],[2],[15]$} \\
\hline Government support, laws and policy & {$[24],[12],[2],[13],[14],[10]$} \\
\hline Human resources & {$[24],[2],[13]$} \\
\hline Industry type & [25] \\
\hline information security culture & {$[22]$} \\
\hline Internal versus external technologies & {$[2],[17],[13]$} \\
\hline Interpret unstructured data & {$[2],[1]$} \\
\hline $\begin{array}{l}\text { IS competence/IT structure (infrastruc- } \\
\text { ture) }\end{array}$ & {$[24],[2],[14],[10],[25],[15]$} \\
\hline IS fashion & {$[24],[2]$} \\
\hline IT expertise & [24], [14] \\
\hline Knowledge about Big Data & {$[2],[17],[13]$} \\
\hline Leaders' attitude towards change & [15] \\
\hline Management support for Big Data & {$[22],[24],[18],[2],[10],[25],[15]$} \\
\hline Market turbulence & {$[24],[2]$} \\
\hline Marketing and inventory & {$[2],[13]$} \\
\hline Network challenges & {$[2],[17],[13]$} \\
\hline Observe-ability & {$[24],[2],[14]$} \\
\hline Organizational (learning) culture & {$[22],[2],[13],[18]$} \\
\hline Organizational data environment & {$[2],[25]$} \\
\hline Perceived benefits (advantage) & {$[24],[2],[15],[13],[14],[10],[25],[1]$} \\
\hline Perceived compatibility & {$[22],[24],[2],[25],[15]$} \\
\hline Perceived Simplicity (Ease of use) & {$[22],[2],[15],[18],[13],[14],[10],[25]$} \\
\hline Perceived cost & {$[2],[25]$} \\
\hline Perceived financial readiness & {$[2],[13],[14],[10],[18]$} \\
\hline Perceived usefulness & {$[2],[25]$} \\
\hline Predictive analytic accuracy & {$[2]$} \\
\hline Relative advantage & {$[24],[2],[13],[14],[10],[15]$} \\
\hline Risks of outsourcing & {$[22],[2]$} \\
\hline Security and privacy & {$[22],[24],[2]$} \\
\hline Staffing & {$[2],[1],[18]$} \\
\hline Supply chain connectivity & [10] \\
\hline system integration & {$[2],[1]$} \\
\hline Technological capability & {$[2]$} \\
\hline $\begin{array}{l}\text { Technology readiness/ technology re- } \\
\text { sources }\end{array}$ & {$[24],[2],[14],[10],[15],[18]$} \\
\hline Trading partner adoption/ readiness & {$[24],[2]$} \\
\hline Training & {$[2],[1],[18]$} \\
\hline Trial ability & {$[24],[2]$} \\
\hline Vendor support & {$[2],[17],[13]$} \\
\hline Willingness to change & {$[18]$} \\
\hline Predictive analytic accuracy & {$[2]$} \\
\hline
\end{tabular}


Table 3: Reliability Statistics

\begin{tabular}{|l|l|l|}
\hline $\begin{array}{l}\text { Cronbach's al- } \\
\text { pha }\end{array}$ & $\begin{array}{l}\text { Cronbach's alpha Based on Stan- } \\
\text { dardized Items }\end{array}$ & $\begin{array}{l}\text { of } \\
\text { Items }\end{array}$ \\
\hline .867 & .892 & 50 \\
\hline
\end{tabular}

Table 4: KMO and Bartlett's test

\begin{tabular}{|l|l|l|}
\hline \multicolumn{2}{|l|}{$\begin{array}{l}\text { Kaiser-Meyer-Olkin measure of sampling ad- } \\
\text { equacy }\end{array}$} & .916 \\
\hline \multirow{3}{*}{ Bartlett's test for sphericity } & $\begin{array}{l}\text { Approx. Chi- } \\
\text { Square }\end{array}$ & 1628.317 \\
& $\begin{array}{l}\text { df } \\
\text { Sig. }\end{array}$ & 846 \\
& Sig. & .000 \\
\hline
\end{tabular}

Table 5: Total Variance Explained

\begin{tabular}{|c|c|c|c|c|c|c|c|c|c|}
\hline \multicolumn{4}{|c|}{ Component Initial Eigenvalues } & \multicolumn{3}{|c|}{$\begin{array}{l}\text { Extraction Sums of } \\
\text { Squared Loadings }\end{array}$} & \multicolumn{3}{|c|}{$\begin{array}{l}\text { Rotation Sums of } \\
\text { Squared Loadings }\end{array}$} \\
\hline & Total & $\begin{array}{l}\text { Variance } \\
(\%)\end{array}$ & $\begin{array}{l}\text { Cumulativ } \\
(\%)\end{array}$ & Total & $\begin{array}{l}\text { Variance } \\
(\%)\end{array}$ & $\begin{array}{l}\text { Cumulative } \\
(\%)\end{array}$ & Total & $\begin{array}{l}\begin{array}{l}\text { Varian } \\
(\%)\end{array} \\
\end{array}$ & $\begin{array}{l}\text { Ceumulative } \\
(\%)\end{array}$ \\
\hline 1 & 26.368 & 36.080 & 36.080 & 26.368 & 36.080 & 36.080 & 7.819 & 11.644 & 11.644 \\
\hline 2 & 8.116 & 11.105 & 47.185 & 8.116 & 11.105 & 47.185 & 8.730 & 13.001 & 24.645 \\
\hline 3 & 6.540 & 8.949 & 56.134 & 6.540 & 8.949 & 56.134 & 7.694 & 11.458 & 36.103 \\
\hline 4 & 5.342 & 7.310 & 63.444 & 5.342 & 7.310 & 63.444 & 6.173 & 9.192 & 45.295 \\
\hline 5 & 4.390 & 6.007 & 69.451 & 4.390 & 6.007 & 69.451 & 5.784 & 8.613 & 53.909 \\
\hline 6 & 3.095 & 4.235 & 73.686 & 3.095 & 4.235 & 73.686 & 4.909 & 7.311 & 61.220 \\
\hline 7 & 2.716 & 3.716 & 77.402 & 2.716 & 3.716 & 77.402 & 3.775 & 5.622 & 66.842 \\
\hline 8 & 2.487 & 3.403 & 80.805 & 2.487 & 3.403 & 80.805 & 3.580 & 5.331 & 72.173 \\
\hline 9 & 2.225 & 3.045 & 83.850 & 2.225 & 3.045 & 83.850 & 3.160 & 4.707 & 76.880 \\
\hline 10 & 1.843 & 2.522 & 86.371 & 1.843 & 2.522 & 86.371 & 3.344 & 4.980 & 81.860 \\
\hline 11 & 1.581 & 2.163 & 88.535 & 1.581 & 2.163 & 88.535 & 3.002 & 4.471 & 86.330 \\
\hline 12 & 1.326 & 1.814 & 90.349 & 1.326 & 1.814 & 90.349 & 2.698 & 4.019 & 90.349 \\
\hline 13 & 0.946 & 1.531 & 91.880 & & & & & & \\
\hline 14 & 0.865 & 1.184 & 93.064 & & & & & & \\
\hline 15 & 0.791 & 1.082 & 94.146 & & & & & & \\
\hline 16 & 0.733 & 1.003 & 95.149 & & & & & & \\
\hline 17 & 0.669 & 0.915 & 96.065 & & & & & & \\
\hline 18 & 0.578 & 0.791 & 96.856 & & & & & & \\
\hline 19 & 0.537 & 0.735 & 97.590 & & & & & & \\
\hline 20 & 0.492 & 0.673 & 98.264 & & & & & & \\
\hline 21 & 0.445 & 0.609 & 98.872 & & & & & & \\
\hline 22 & 0.358 & 0.490 & 99.362 & & & & & & \\
\hline 23 & 0.284 & 0.389 & 99.751 & & & & & & \\
\hline 24 & 0.182 & 0.249 & 100.000 & & & & & & \\
\hline 25 & 0.000 & 0.000 & 100.000 & & & & & & \\
\hline 26 & 0.000 & 0.000 & 100.000 & & & & & & \\
\hline - & - & . & . & & & & & & \\
\hline 50 & 0.000 & 0.000 & 100.000 & & & & & & \\
\hline
\end{tabular}




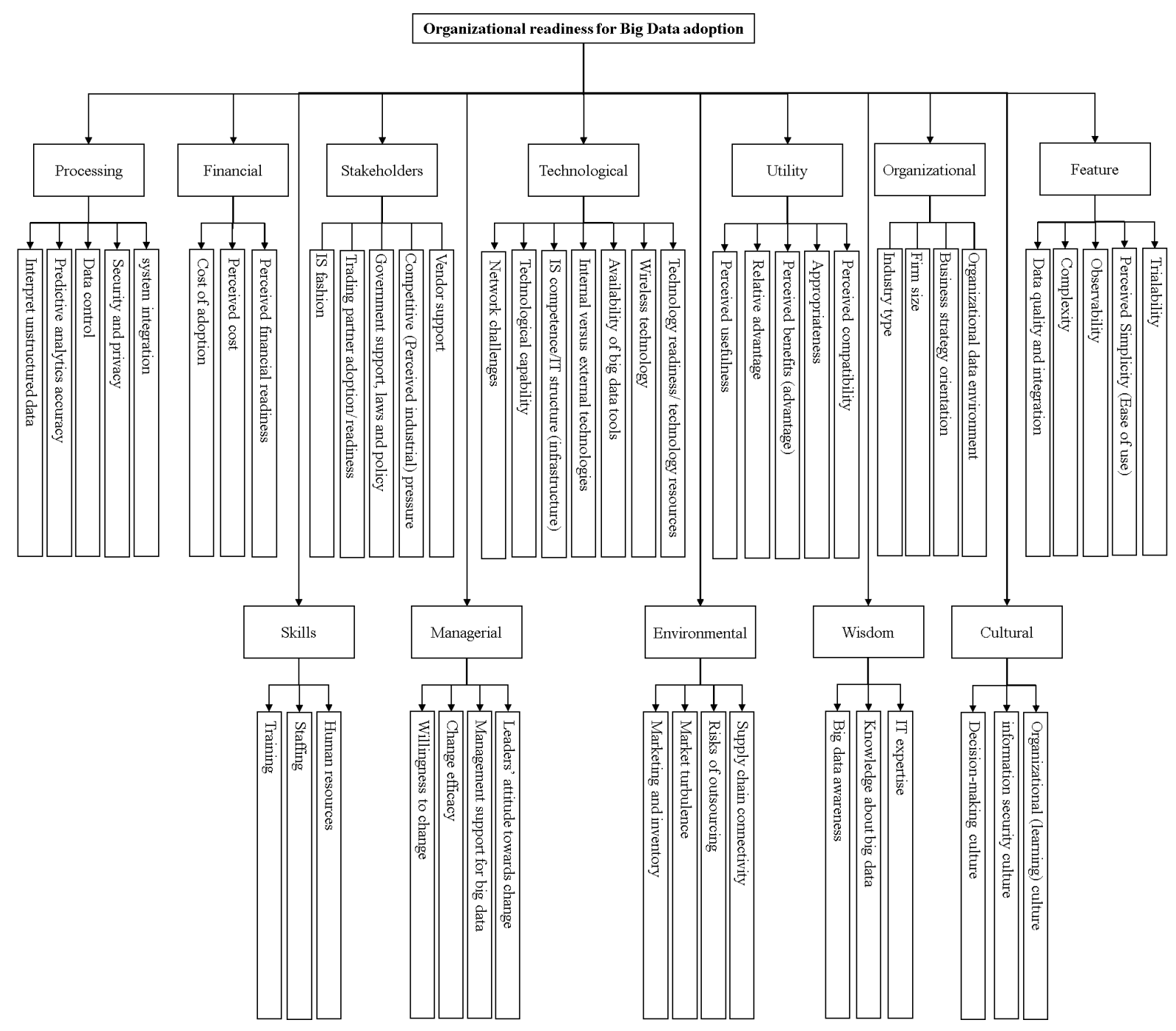

Figure 2: Hierarchical structure of organizational readiness evaluation

\section{Determining the importance of criteria by FBWM}

In this stage, the importance of the identified criteria will be determined. These criteria and their weights can be used to assess organizational readiness for Big Data adoption. According to Best-Worst Method (BWM) - introduced by Rezaei [21] - the best and the worst criteria are identified first by the decision-maker, followed by pairwise comparisons conducted between each of these two criteria and the other criteria [20]. A MaxiMin problem is then formulated and solved to determine the weights of different criteria. The salient features of the proposed method, compared to the existing multicriteria decision making (MCDM) methods, are: (1) it requires fewer comparison data; (2) it leads to more consistent comparisons, which means that it produces more reliable results". Fuzzy Best-Worst Method (FBWM) is executed in 5 steps [7].

Step 1. Build the decision criteria system. In this step, we consider the criteria $\left\{C_{1}, C_{2}, \ldots, C_{n}\right\}$ that should be used to arrive at a decision.

Step 2. Determining the best (e.g., most important) and the worst (e.g., least important) criteria. In this step, the decision-maker identifies the best, and the worst criterion in general and no comparison is made at this stage.

Step 3. Execute the fuzzy reference comparisons for the best criterion. The resulting fuzzy Best-to-Others vector would be $\tilde{A}_{B}=\left(\tilde{a}_{B 1}, \tilde{a}_{B 2}, \ldots, \tilde{a}_{B n}\right)$ where $\tilde{a}_{B j}$ indicates the fuzzy preference of the best criterion over criterion $\mathrm{j}$ and it is clear that $\tilde{a}_{B B}=(1,1,1)$.

Step 4. Execute the fuzzy reference comparisons for the worst criterion. The resulting 
fuzzy Others-to-Worst vector would be $\widetilde{A}_{W}=\left(\tilde{a}_{1 W}, \tilde{a}_{2 W}, \ldots, \tilde{a}_{n W}\right)$, where $\tilde{a}_{i W}$ indicates the preference of the criterion $\mathrm{j}$ over the worst criterion and it is clear that $\widetilde{a}_{W W}=(1,1,1)$. Step 5. Finding the optimal fuzzy weights $\left(\widetilde{\mathrm{W}}_{1}^{*}, \widetilde{\mathrm{W}}_{2}^{*}, \ldots, \widetilde{\mathrm{W}}_{\mathrm{n}}^{*}\right)$. The optimal fuzzy weight for the criteria is the one where, for each pair of $\frac{\tilde{W}_{B}}{\widetilde{\mathrm{W}}_{j}}$ and $\frac{\tilde{W}_{j}}{\widetilde{\mathrm{W}}_{w}}$, we have $\frac{\tilde{W}_{B}}{\tilde{W}_{j}}=\tilde{a}_{B j}$ and $\frac{\tilde{W}_{j}}{\tilde{W}_{w}}=\tilde{a}_{j w}$. To satisfy these conditions for all $\mathrm{j}$, we should find a solution where the maximum absolute differences $\left|\frac{W_{B}}{W_{j}}-a_{B j}\right|$ and $\left|\frac{W_{j}}{W_{w}}-a_{j w}\right|$ for all $\mathrm{j}$ is minimized. The optimization problem to determine the optimal weight of the criteria $\left(W_{1}^{*}, W_{2}^{*}, \ldots, W_{n}^{*}\right)$ is presented as the model (1):

$$
\begin{gathered}
\operatorname{Min}_{\operatorname{Max}}{ }_{j}\left\{\left|\frac{W_{B}}{W_{j}}-a_{B j}\right|,\left|\frac{W_{j}}{W_{w}}-a_{j w}\right|\right\} \\
\text { s.t : } \\
\sum_{j=1}^{n} W_{j}=1 \\
W_{j} \geq 0, \text { for all } j
\end{gathered}
$$

Then, model (1) turns into the following optimization problem with nonlinear constraints:

$$
\begin{gathered}
\text { Min } \widetilde{\wp} \\
\text { s.t : } \\
\left|{\widetilde{\mathrm{W}_{\mathrm{B}}}}_{\mid \widetilde{\mathrm{W}}_{\mathrm{j}}}-\widetilde{\mathrm{a}}_{\mathrm{Bj}}\right| \leq \widetilde{\wp}, \text { for all } \mathrm{j} \\
\left|\frac{\widetilde{\mathrm{W}}_{\mathrm{j}}}{\widetilde{\mathrm{W}}_{\mathrm{w}}}-\widetilde{\mathrm{a}}_{\mathrm{jw}}\right| \leq \widetilde{\wp}, \text { for all } \mathrm{j} \\
\sum_{\mathrm{j}=1}^{\mathrm{n}} \mathrm{R}\left(\widetilde{\mathrm{W}}_{\mathrm{j}}\right)=1 \\
l_{j}^{w} \leq m_{j}^{w} \leq u_{j}^{w} \\
l_{j}^{w} \geq 0 \\
\mathrm{j}=1,2, \ldots, \mathrm{n}
\end{gathered}
$$

Where $\widetilde{\wp}=\left(l_{j}^{w}, m_{j}^{w}, u_{j}^{w}\right)$. Considering $l_{j}^{w} \leq m_{j}^{w} \leq u_{j}^{w}$, we suppose $\widetilde{\wp}^{*}=\left(k^{*}, k^{*}, k^{*}\right), \quad k^{*} \leq l^{\wp}$, then nonlinear model (2) can turn into the model (3):

$$
\begin{gathered}
\text { Min } \widetilde{\wp}^{*} \\
\text { s.t : } \\
\left|\frac{\left(l_{B}^{w}, l_{B}^{w}, l_{B}^{w}\right)}{\left(l_{j}^{w}, l_{j}^{w}, l_{j}^{w}\right)}-\left(l_{B j}, m_{B j}, u_{B j}\right)\right| \leq\left(k^{*}, k^{*}, k^{*}\right), \text { for all } \mathrm{j} \\
\left|\frac{\left.\left(l_{j}^{w}, l_{j}^{w}, l_{j}^{w}\right)\right)}{\left.l_{W}^{w}, l_{W}^{w}, l_{W}^{w}\right)}-\left(l_{j W}, m_{j W}, u_{j W}\right)\right| \leq\left(k^{*}, k^{*}, k^{*}\right), \text { for all } \mathrm{j} \\
\sum_{\mathrm{j}=1}^{\mathrm{n}} \mathrm{R}\left(\widetilde{\mathrm{W}}_{\mathrm{j}}\right)=1 \\
l_{j}^{w} \leq m_{j}^{w} \leq u_{j}^{w} \\
l_{j}^{w} \geq 0 \\
\mathrm{j}=1,2, \ldots, \mathrm{n}
\end{gathered}
$$

By solving model (3), the optimal weights $\left(\mathrm{W}_{1}^{*}, \mathrm{~W}_{2}^{*}, \ldots, \mathrm{W}_{\mathrm{n}}^{*}\right)$ are obtained.

To determine the weights of the criteria (using FBWM), first, a customized questionnaire was devised and distributed among 18 experts. Next, based on the opinions of the respondent experts, the most and the least essential criteria were established. In the next step, the Best-to-Others preference vector was determined. To do this, all 18 experts were asked to specify their most preferred criterion compared with the other criteria. Afterward, the Others-to-Worst preference vector was also determined. The process of determining the latter was the same as that of the Best-to-Others vector. In the end, the optimization problem was expanded based on Model (3) of the FBWM. After solving the model above using the computer software MATLAB, the final weights of the criteria were calculated (Table 6) and depicted in a diagram (Figure 3).

Table 6: Criteria weights for organizational readiness assessment

\begin{tabular}{|l|l|l|l|l|l|l|}
\hline Criterion & Technological & Wisdom & Feature & Cultural & Financial & Skills \\
\hline weight & 0.126 & 0.028 & 0.206 & 0.035 & 0.063 & 0.058 \\
\hline Criterion & Stakeholders & Managerial & Utility & Environmental & Organizational & Processing \\
\hline weight & 0.122 & 0.091 & 0.154 & 0.029 & 0.031 & 0.056 \\
\hline
\end{tabular}




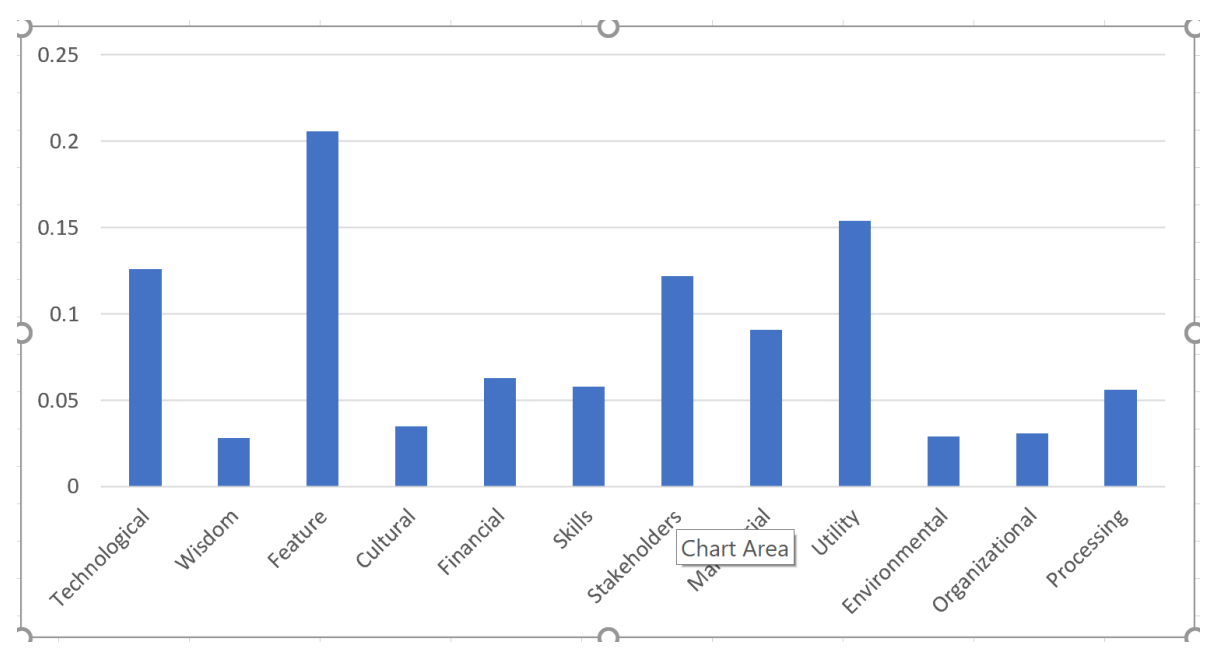

Figure 3: Criteria weights

\section{Conclusion}

Big Data is one of the issues that are considered by practitioners and scholars due to the high volume and speed of data exchange in today's world. The study investigates the prospects of developing frameworks for Big Data adoption on well-established methodologies. In this paper, a proper Procedure applied to identify effective criteria to evaluate organizational readiness for Big Data adoption and determine the relative importance of decision-making criteria. Here, in this study, fifty initial criteria are taken up for the present work based on a comprehensive literature review. The SPSS software has been utilized for ease of analysis, reduction of items, and examining the interrelations among the variables. Finally, fifty initial criteria are classified into12 criteria and used for further analysis. The hierarchical leveling of these criteria have been established.

In further research, the implications of the calculated weights will be analyzed. This work developed an MCDM approach using the FBWM for the assessment of organizational readiness. Results showed that Big Data features criterion (Including Trail ability, Observe-ability ...) is the most critical criterion for Big Data adoption. The methodology developed in this paper helps the decisionmaker in identifying organization weaknesses for adopting Big Data by considering both conflicting quantitative and qualitative evaluation criteria in real-life applications. Researchers can use more quantitative methods such as ISM, (fuzzy) MICMAC, (fuzzy) DEMATEL, and FCM to model the inter-relationships between criteria.

\section{Acknowledgements}

This work was supported by the Portuguese Foundation for Science and Technology (FCT) through the Strategic Program UID/EEA/00066/2019 and the Center of Technology and Systems (CTS).

\section{Author contributions}

The authors contributed equally to this work.

\section{Conflict of interest}

The authors declare no conflict of interest.

\section{References}

[1] Almoqren N.; Altayar, M. (2016). The motivations for big data mining technologies adoption in saudi banks, 2016 4th Saudi Int. Conf. Inf. Technol. Big Data Anal., KACSTIT, 2016. 
[2] Baig, M.I.; Shuib L.; Yadegaridehkordi, E. (2019). Big data adoption: State of the art and research challenges, Inf. Process. Manag., 56(6), 102095, 2019.

[3] Camarinha-Matos, L.M.; Fornasiero, R.; Ramezani, J.; Ferrada, F. (2019). Collaborative Networks: A Pillar of Digital Transformation, Appl. Sci., 9(24), 5431, 2019.

[4] Erl, T.; Khattak, W.; Buhler, P. (2016). Big Data Fundamentals Concepts, Drivers \& Techniques 1st edn.,Prentice Hall, 2016.

[5] Filip, F.G.; Zamfirescu, C.B.; Ciurea, C. (2017). Computer Supported Collaborative Decision Making, Springer, 2017.

[6] Gantz, B.J.; Reinsel, D. (2012). The digital universe in 2020: Big data, bigger digital shadows, and biggest growth in the far east, IDC iView: IDC Anal, Future, 2007, 1-16, 2012.

[7] Guo, S.; Zhao, H. (2017). Fuzzy best-worst multi-criteria decision-making method and its applications, Knowledge-Based Systems, 121, 23-31, 2017.

[8] Izhar T. A.T.; Shoid, M.S.M. (2016). A Research Framework on Big Data awareness and Success Factors toward the Implication of Knowledge Management: Critical Review and Theoretical Extension, Int. J. Acad. Res. Bus. Soc. Sci., 6(4), 325-338, 2016.

[9] Konishi, S. (2014). Introduction to multivariate analysis: Linear and nonlinear modelings, CRC Press Taylor \& Francis Group, New York, 2014.

[10] Lai, Y.; Sun, H.; Ren, J. (2017). Understanding the determinants of big data analytics, Int. J. Logist. Manag., 2017.

[11] Low, C.; Chen, Y.; Wu, M. (2011). Understanding the determinants of cloud computing adoption, Ind. Manag. Data Syst., 111(7), 1006-1023, 2011.

[12] Mikalef, P.; Pappas, I.O.; Krogstie, J.; Giannakos, M. (2018). Big data analytics capabilities: a systematic literature review and research agenda, Inf. Syst. E-bus., 16(3), 547-578, 2018.

[13] Mneney J.; Van Belle, J.P. (2016). Big Data capabilities and readiness of South African retail organisations, Cloud Syst. Big Data Eng. Conflu., 279-286, 2016.

[14] Nam, D.W.; Kang, D.; Kim, S.H. (2015). Process of big data analysis adoption: Defining big data as a new IS innovation and examining factors affecting the process, Proc. Annu. Hawaii Int. Conf. Syst. Sci., 2015(March), 4792--4801, 2015.

[15] Nguyen T.; Petersen, T.E. (2017). Technology Adoption in Norway: Organizational Assimilation of Big Dat, a. Technol. Adopt. Norw. Organ. Assim. Big Data, 24, 2017.

[16] Ochieng, G. F. O. (2015). The Adoption of Big Data Analytics by Supermarkets in Kisumu County, University of Nairobi, 2015.

[17] Olszak, C. M.; Mach-Król, M. (2018). A conceptual framework for assessing an organization's readiness to adopt big data, Sustain., 10(10), 1-27, 2018.

[18] Pappas, I.O; Mikalef, P.; Dwivedi, Y.K.; Jaccheri, L.; Krogstie, J.; Mäntymäki, M.(2019). Digital Transformation for a Sustainable Society in the 21st Century, Lect. Notes Comput. Sci., 1(August), 451-463, 2019.

[19] Ramezani, J.; Camarinha-Matos, L.M. (2019). A collaborative approach to resilient and antifragile business ecosystems,In: 7th International Conference on Information Technology and Quantitative Management (ITQM): Information technology and quantitative management based on Artificial Intelligence, Procedia Computer Science, 162, 604-613, 2019. 
[20] Ramezani, J.; Sadraei, M.; Nasrollahi, M. (2019). Identification and Ranking of Effective Criteria in Evaluating Resilient IT Project Contractors, In: Proceedings of YEF-ECE 2019, 3rd Young Engineers Forum, IEEE Xplore, 2019.

[21] Rezaei, J. (2015). Best-worst multi-criteria decision-making method, Omega, 53, 49—57, 2015.

[22] Salleh K. A., Janczewski, L. (2016). Adoption of Big Data Solutions: A study on its security determinants using Sec-TOE Framework, International Conference on Information Resources Proceedings, 66, 2016.

[23] Shah, N.; Irani, Z.; Sharif, A. M. (2017). Big data in an HR context: Exploring organizational change readiness, employee attitudes and behaviors, J. Bus. Res., 70, 366 - 378, 2017.

[24] Sun, S.; Cegielski, C.; Jia, L.; J Hal, D. (2018). Understanding the Factors Affecting the Organizational Adoption of Big Data, J. Comput. Inf. Syst.,58(3), 193-203, 2018.

[25] Verma, S.; Bhattacharyya, S.S. (2017). Perceived strategic value-based adoption of Big Data Analytics in emerging economy: A qualitative approach for Indian firms, J. Enterp. Inf. Manag., $30(3), 354-382,2017$.

[26] [Online]. Available: https://www.forbes.com/sites/louiscolumbus/2018/12/23/big-data-analyticadoption-soared-in-the-enterprise-in-2018, forbes, 2018.

[27] [Online]. Available: https://www.slideshare.net/denisreimer/big-data-industry-insights-2015, Gartner, 2015.

\section{(c) (1) (8)}

Copyright (C)2020 by the authors. Licensee Agora University, Oradea, Romania.

This is an open access article distributed under the terms and conditions of the Creative Commons Attribution-NonCommercial 4.0 International License.

Journal's webpage: http://univagora.ro/jour/index.php/ijccc/

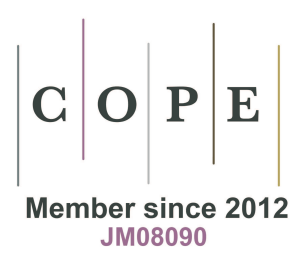

This journal is a member of, and subscribes to the principles of, the Committee on Publication Ethics (COPE).

https://publicationethics.org/members/international-journal-computers-communications-and-control

Cite this paper as:

Nasrollahi, M.; Ramezani, J. (2020). A Model to Evaluate the Organizational Readiness for Big Data Adoption, International Journal of Computers Communications \& Control, 15(3), 3874, 2020. https://doi.org/10.15837/ijccc.2020.3.3874 